\title{
Identification of infectious salmon anaemia virus in Atlantic salmon from Nova Scotia (Canada): evidence for functional strain differences
}

\author{
Rachael J. Ritchie ${ }^{1}$, Marcia Cook ${ }^{1}$, Krista Melville ${ }^{1}$, Nathalie Simard ${ }^{1}$, \\ Roland Cusack ${ }^{2}$, Steve Griffiths ${ }^{1, *}$ \\ ${ }^{1}$ Research and Productivity Council, 921 College Hill Rd., Fredericton, New Brunswick E3B 6Z9, Canada \\ ${ }^{2}$ Nova Scotia Department of Fisheries and Aquaculture, Box 550, NSAC Mail Room, Cumming Hall, Truro, \\ Nova Scotia B2N 5E3, Canada
}

\begin{abstract}
Infectious salmon anaemia (ISA) is a serious disease responsible for high morbidity in farmed Atlantic salmon Salmo salar in Norway, Scotland and New Brunswick, Canada. Recent attempts to identify different strains of ISA virus (ISAV) based on nucleotide sequence variation have shown that the Norwegian and Scottish samples are similar to one another but markedly different from New Brunswick samples. These data may suggest the presence of different strains on each side of the Atlantic but no functional difference has been found with either strain. We describe the first identification and characterisation of ISAV in Atlantic salmon from Nova Scotia, Canada. Further, salmon infected with the Nova Scotia ISAV do not show typical ISAV pathology or mortality. Sequencing of this new strain showed it to possess greater similarity to ISAV from Norway and Scotland than to ISAV from New Brunswick. These findings are discussed in terms of a possible origin of the Nova Scotia ISAV strain and the existence of an avirulent ISAV strain. The impact of current strain variation studies on our knowledge of ISAV is also discussed.
\end{abstract}

KEY WORDS: ISAV $\cdot$ Strain variation $\cdot$ Genome characterisation

\section{INTRODUCTION}

The infectious salmon anaemia virus (ISAV) is an orthomyxovirus-like virus that causes high mortality in farmed Atlantic salmon. The virus was first identified in Norway in 1984 (Thorud \& Djupvik 1988) and has since been found in Scotland (Rodger et al. 1998, Rowley et al. 1999), New Brunswick, Canada (Mullins et al. 1998, Blake et al. 1999, Bouchard et al. 1999, Lovely et al. 1999) and most recently Chile (F. S. Kibenge, pers. comm.). Affected fish show severe anaemia, congestion of the liver, spleen and foregut, and haemorrhagic liver necrosis (Thorud \& Djupvik 1988, Evensen et al. 1991). In Canada infectious salmon anaemia has become the most serious disease

\footnotetext{
${ }^{*}$ Corresponding author. E-mail: sgriffit@rpc.unb.ca
}

to have affected Atlantic salmon aquaculture, having been responsible for over 30 million (Canadian) dollars of direct loss to stock (New Brunswick Department of Fisheries and Aquaculture pers. comm.). Consequently, surveillance programmes based on immunological assays and RT-PCR were established to monitor the disease in Atlantic Canada.

Characterisation of the morphological and replicational properties of ISAV using electron microscopy and growth in salmon head kidney (SHK) (Dannevig et al. 1995, Nylund et al. 1995c) and later genomic characterisation (Mjaaland et al. 1997, Falk et al. 1997) has suggested that the ISAV has high similarity to viruses in the Orthomyxoviridae family, but probably is a new distinct family or sub-family (Krossøy et al. 1999, Cunningham \& Snow 2000). The ISAV is a segmented, negative-stranded RNA virus consisting of 8 RNA segments ranging in size from 1.0 to $2.3 \mathrm{~kb}$ (Mjaaland et 
al. 1997). To date, 2 of these segments have been cloned and sequenced: segment 2 contains the polymerase B gene, and segment 8 contains the non-structural (NS) genes 1 and 2 (Mjaaland et al. 1997, Krossøy et al. 1999). Genomic characterisation and the coincident establishment of RT-PCR assays for rapid detection of ISAV (Mjaaland et al. 1997) is now being followed by attention to strain variation of ISAV.

Interest in ISAV strain variation, and its implications for current surveillance and monitoring viral evolution, has been highlighted by recent reports of ISAV sequence variation in samples from different geographic areas. Several groups have found nucleotide variation in ISAV segments 2 and 8 between samples from New Brunswick and those from Norway and Scotland, leading to the belief that different strains exist on each side of the Atlantic (Cunningham \& Snow 2000, Kibenge et al. 2000). Not surprisingly, several groups have found that RT-PCR using certain primer pairs produces false negative results when used to amplify certain strains (Cunningham \& Snow 2000, Ritchie et al. unpubl. data).

In the present study we document the first identification of ISAV in Atlantic salmon in Nova Scotia, Canada. Interestingly, this strain is not associated with typical ISAV pathology or mortality. To characterise this new strain of ISAV we compared the sequence of 2 genomic segments with that of the Norwegian, Scottish and New Brunswick isolates and found it is most similar to ISAV from Norway and Scotland. We discuss our finding in light of the possible origin of the Nova Scotia isolate and discuss the implications of our finding on genome structure and future strain variation studies.

\section{MATERIALS AND METHODS}

Fish sampling, rearing conditions and history. Four yr old Atlantic salmon broodstock were housed in $15 \mathrm{~m}^{2}$ cages at a brackish water site $(24 \%$ ) in northern Nova Scotia. In November 1998, 350 randomly selected broodstock were killed after spawning. A standard necropsy procedure was performed on all fish and blood, gill, kidney, pyloric ceca and spleen samples collected for viral and bacterial cultures. Sixty fish were individually sampled for viruses while the other samples consisted of 58 pools of 5 fish per pool.

Two yr old fish held at the site described above were transferred to 3 other farms in Nova Scotia. Between January and September 1999 a minimum of 30 moribund fish were necropsied and sampled for viruses at the farms receiving the transported fish. Fish from 2 sites close to a 'suspect' farm were also monitored for the presence of ISAV. In all, 227 moribund fish (at least
30 fish from each of the 5 farms mentioned) were tested for ISAV. To monitor fish from these 2 sites, sections of mid-kidney were excised from moribund fish and tested for ISAV. Kidney tissue was cultured on SHK cells (see below), analysed by RT-PCR (see below) and screened using indirect fluorescent antibody technique (Dannevig et al. 1995).

Wild Atlantic salmon were collected from the East River, Tusket River and Liscombe River, Nova Scotia. A total of 75 fish were non-lethally sampled by collecting $1 \mathrm{ml}$ of blood from the caudal vein of anaesthetised fish. The sample was homogenised, diluted to 1:50 and processed as outlined on SHK cells. Blood samples were cultured on SHK, CHSE-214 and EPC (carp papilloma) cell lines. Blood samples were also tested by RT-PCR as described below.

Cell culture. Pools of organs collected by necropsy were homogenised in 5 volumes of Hanks' balanced salt solution (ICN Biomedicals Inc., Aurora, OH, USA) and homogenised at high speed for 2 min in a Stomacher 80 laboratory blender (Tekmar-Dohrmann, Cincinnati, OH, USA). A 10-fold dilution, prepared for each homogenate in Hanks' balanced salt solution, was centrifuged at $2800 \mathrm{rpm}(1790 \times g)$ in a GS-6R centrifuge (Beckman Instruments Inc., Fullerton, CA, USA) followed by filtration through $0.45 \mu \mathrm{m}$ Acrodisc syringe filters (Pall Gelman Science, Ann Arbor, MI, USA). Monolayers of CHSE-214 and SHK cells in 24well culture plates (80 to $100 \%$ confluency), which had been prepared 24 to $48 \mathrm{~h}$ earlier and sealed with Falcon 3073 pressure-sensitive film (Becton Dickinson and Co., Oxnard, CA, USA), were washed with $1 \mathrm{ml}$ of Hanks' balanced salt solution and inoculated with fil-

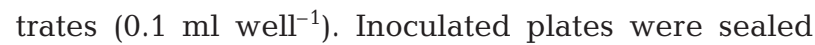
with pressure-sensitive film and centrifuged at $4^{\circ} \mathrm{C}$ for $1 \mathrm{~h}$ at $2800 \mathrm{rpm}(1430 \times \mathrm{g})$ in a GS-6R centrifuge. CHSE-214 plates were topped with $1 \mathrm{ml}$ of MEM (Hanks' salts, L-glutamine) (Gibco BRL, Burlington, ON, Canada) supplemented with $2 \%$ FBS (Gibco BRL) and $1 \times$ antibiotic-antimycotic (Gibco BRL) while SHK plates were topped with Leibovitz's L-15 medium (L-glutamine) (Gibco BRL) supplemented with 5\% FBS and $1 \times$ antibiotic-antimycotic. All inoculated plates were incubated at $15^{\circ} \mathrm{C}$ for at least $30 \mathrm{~d}$ and monitored for cytopathic effects at least once a week. CHSE-214 cells used in tissue culture were grown in MEM (Earle's salts) (Gibco BRL) supplemented with 10\% FBS, $0.01 \mathrm{M}$ Hepes buffer (ICN Biomedicals Inc.) and 2 mM L-glutamine (ICN Biomedicals Inc). SHK cells were maintained in Leibovitz's L-15 medium supplemented with 5\% FBS, $40 \mathrm{mM} \beta$-mercaptoethanol (Gibco BRL) and 1× antibiotic-antimycotic.

RT-PCR. RNA from the tissue being studied was isolated using Trizol or Trizol LS (Gibco BRL) according to the manufacturer's instructions. RT-PCR was per- 
formed using the Ready-to-go RT-PCR beads and protocol (Amersham Pharmacia Biotech, Uppsala, Sweden). Briefly, $2 \mu \mathrm{g}$ of RNA and $0.5 \mu \mathrm{g}$ of random hexanucleotide primers in a volume of $40 \mu \mathrm{l}$ were added to the RT-PCR beads. Following resuspension, the reaction was incubated at $42^{\circ} \mathrm{C}$ for $30 \mathrm{~min}$, then $94^{\circ} \mathrm{C}$ for 5 min before being cooled to $4^{\circ} \mathrm{C}$. For cDNA amplification, primers were added to a final concentration of $0.4 \mu \mathrm{M}$ and $\mathrm{MgCl}_{2}$ to a final concentration of $2.0 \mathrm{mM}$. PCR conditions were 35 cycles of $94^{\circ} \mathrm{C}$ for $30 \mathrm{~s}, 60^{\circ} \mathrm{C}$ for $45 \mathrm{~s}$ and $72^{\circ} \mathrm{C}$ for $90 \mathrm{~s}$. All reactions were performed in a Gene Amp 9600 (PE Applied Biosystems, Foster City, CA, USA). RT-PCR products were analysed on $8 \%$ or $11 \%$ acrylamide gels and visualised by ethidium bromide, silverstaining or both. Primers employed for PCR and sequence analysis were $245 \mathrm{~V}$ (5'-GGA TGT GGG ACA TAG GGA AC-3'), 791L (5'-CAC GAC GAG CAT TGT CTG TT-3'), 991V (5'-GAA CTT GGG ATA AAG GGA CC-3'), 1605L (5'-TGG CTT GGC TGA AAG AGA GG-3'), ISAV-I (5'-CGA GCG ACG ATG ACT CTC TAC-3') and ISAV-II (5'-ACC CAA ATA TCC CAT TCA ACA-3'). All primers were designed from previously published sequences (Y10404 and AJ002475).

RT-PCR was performed on RNA isolated from kidney tissue of infected salmon from New Brunswick (Fundy) or Nova Scotia (Cape Breton), and on RNA isolated from ISAV cultures of Scottish (Loch Nevis) and Norwegian (Glesvaer) isolates. Primers ISAV-I and ISAV-II amplify a $592 \mathrm{bp}$ product from segment 8 of the ISAV genome coding for the NS1 and NS2 genes, and the primer pairs $245 \mathrm{~V} / 991 \mathrm{~L}$ and $991 \mathrm{~V} / 1606 \mathrm{~L}$ amplify a 547 and 615 bp region respectively of ISAV segment 2 encoding the polymerase gene. The portion of segment 8 analysed is covered completely by sequence from Krossøy et al. (1999) (AJ012285) and overlaps at the $5^{\prime}$ end the sequence from Blake et al. (1999) (AF095255).

Sequencing. RT-PCR products were cleaned using PCR clean up kit (Quiagen, Chatsworth, CA, USA). Thirty to $90 \mathrm{ng}$ of DNA was sequenced using $3.2 \mathrm{pmol}$ primer and $8 \mu$ Big Dye Terminators (PE Applied Biosystems). Sequencing reactions were electrophoresed on an ABI310 Genetic Analyser (PE Applied Biosystems) and sequences were analysed using the Sequencher program (Genecodes, Ann Arbor, MI, USA).

\section{RESULTS}

The ISAV strain described here was first identified adventitiously as a result of a broodstock surveillance program in December 1998. Although obvious cytopathic effects characteristic of ISAV infection were not observed for any of the samples, closer examination of SHK cultures revealed some aberrancies in the cell monolayer that distinguished them from uninfected controls. A selection of these cultures was analysed by RT-PCR using ISAV primers FA3/RA3 as described by Melville \& Griffiths (1999). A product of the expected size was amplified in 6 of the 29 samples analysed. To confirm identity, amplified products were sequenced. While the products were unequivocally identified as being a portion of ISAV segment 8, the greatest homology was to the Norwegian Glesvaer strain (accession No. AJ012285, Krossøy et al. 1999) rather than the Canadian Fundy strain (accession No. AF109304, Lovely et al. 1999). However, despite the positive identification of ISAV, there were no reports of ISAVrelated mortality at the affected site.

Between the time of sampling and the identification of ISAV infection, 2 yr old Atlantic salmon from the affected site were transported to 3 other aquaculture sites in Nova Scotia. Fish from these 3 sites and 2 adjacent sites were tested for the presence of the virus. In all, 227 moribund fish, at least 30 fish from each site, were tested for ISAV using 3 diagnostic techniques as described above. SHK cell culture of 277 fish from these farms were all negative for ISAV. However, 7 fish tested positive for ISAV by RT-PCR while 3 fish tested positive by the indirect fluorescent antibody technique. There were no abnormal mortalities or pathological changes in the fish populations to suggest clinical disease as a result of ISAV infections.

To further ascertain the origin of the virus, sections of 2 ISAV segments were sequenced and compared with equivalent sequences from Canadian (New Brunswick and Nova Scotia), Scottish and Norwegian samples (Figs 1, 2 \& 3). RT-PCR using primers ISAV-I and ISAVII amplified a product of $592 \mathrm{bp}$ from the Norwegian (Glesvaer) and Scottish (Loch Nevis) isolates, and from 2 isolates from both New Brunswick and Nova Scotia. Sequencing of this fragment using PCR primers revealed that the Norwegian (Glesvaer), Scottish (Loch Nevis) and Nova Scotia samples shared greater than 99\% homology (Fig. 1a). However, all 3 samples showed substantially lower homology with the 2 isolates from New Brunswick ( 89\%) (Fig. 1a).

To compare the amino acid sequence of the isolates, the nucleotide sequence of each isolate was translated in all 3 frames and compared with the predicted protein sequence of the NS1 and NS2 genes encoded by segment 8. Translation of our sequences revealed a large open reading frame (ORF) in each of 2 ORFs, and the presence of many stop codons the third frame. Translation of 1 of the 2 large ORFs was compared with the NS1/ORF3 protein predicted by the Norwegian (Glesvaer/90) sequence in the database (AJ012285) (Fig. 1b). As predicted by nucleotide sequence, the Nova Scotia sequence shared high homology with the Norwegian and Scottish amino acid sequences. For 
(a)

AJ012285
N
S
NS
NB

AJ012285

$\mathrm{N}$
$\mathrm{S}$
$\mathrm{NS}$

NB

AJ012285
N
S
NS
NB

NB

AJ012285
N
S
NS
NB

AJ012285

AJ012285
N
S
NS
NB

AJ012285

N

NS

NB

AJ 012285

$\mathrm{N}$

NS

NB

AJ012285

AJ012285
N
S
NS
NB

AJ012285

N

NS

AJ012285

$\mathrm{N}$
$\mathrm{N}$
$\mathrm{NS}$

NS

AJ012285

$\mathrm{N}$

$\mathrm{S}$

NS
TGTGTGATGA AAGATCCACC GTCTGGAAGC ATGGCGACAC

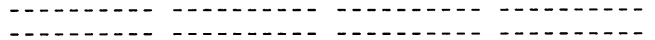

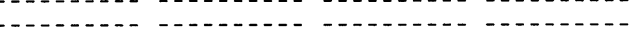

- A-G-G-A-G-

TGATGAGGGA TCACATCAGA AACTGGCTGA AGGAAGAGTC

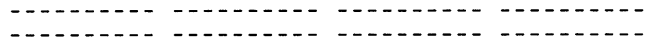

-

- C-- C-O

AGGATGCCAA GACGCGGATG GTGGAGAGGA AAAGTGGGCA

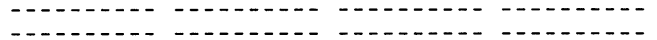

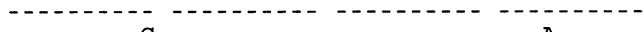

ATGGTGTATG GTATGATTTC ACCAGACATG GCGGAGgAGA

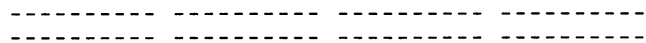

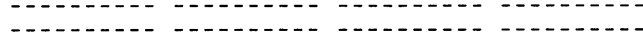

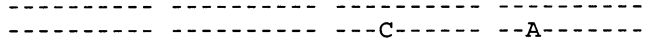

AGACGATGTT GAAGGACCTG AAgACAATGC TACACAGCAG

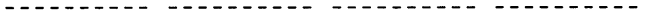

-

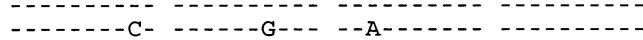

GATGCAGATG TATGCCCTAG GAGCGAGTTC GAAAGCCCTG

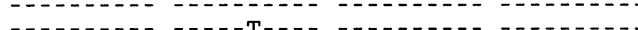

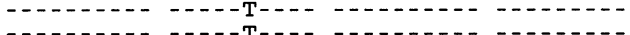

-

GAAACTTTAG AAAAGGCCAT CGTCGCTGCA GTTCATCGAC

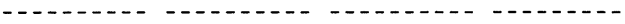

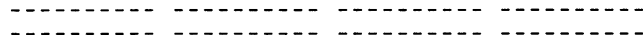

- G-A-D-D - -

TTCCGGCATC CTGCTCGACA GAGAAGATGG TGCTCCTGGG

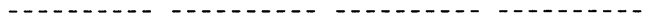

-

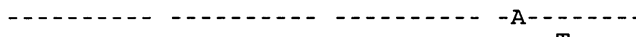

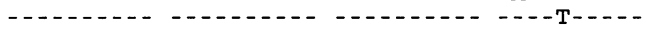

GTACCTGAGAT AAGCCCTGC AGAGAAACTG GAAGCAGAGA

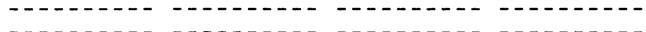

-

GGAAAAAGCT GAGTGAGCTG GACGACAAGA TCTACAAGCT

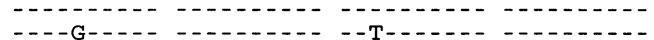

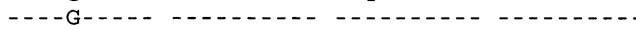

A-- G-A- - - AA-

GAgGAgGAgg CTGAgAAagA TGgAgtACAA GAAGATgGg

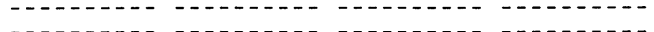

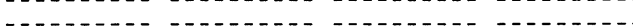

A-DA-
AJ012285

$\mathrm{S}$

NS

NB

AJ012285

$\mathrm{N}$

NS

AJ012285

$\mathrm{N}$

NS

NB

(b)

AJ012285

N

NS

NB

AJ012285

$\mathrm{N}$

NS

NB

AJ012285

$\mathrm{N}$

$\mathrm{N}$

NB

AJ012285

$\mathrm{N}$

NS

NB

(c)

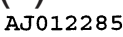

$\mathrm{N}$

NS

NB

AJ012285

N
N
NS

NB

AJ012285

$\mathrm{N}$
$\mathrm{N}$
$\mathrm{NS}$

NS
ATCAACAGGG AAATCGACCA ATTGGAAGAC TCTGTACAAT

- - - - - - -

-

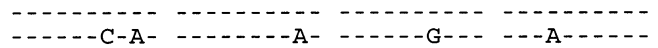

AAATTAATCA TCTCAATACT CATTTATGTT ATACTAAATT

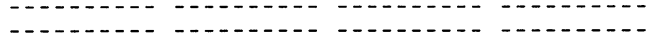

-

- - G-C-T - T T-. T- - -

TGGTGATGAA TCTAAAGATT TCTTGT

-

- - - - - - - - - - -

- - - - - - - - - - -

Fig. 1. Sequence comparison of ISAV in the region flanked by primers ISAVI/ISAVII. (a) Nucleotide sequence; (b) predicted protein sequence of non-structural (NS) gene 1 (open reading frame [ORF] 3); (c) predicted protein sequence of NS2 (ORF1).

AJ012285: database sequence of ISAV from Norway; N: Norway; S: Scotland; NS: Nova Scotia; NB: New Brunswick

these 3 isolates, homology at the nucleotide level $(>99 \%)$ was similar to that at the amino acid level $(>97 \%)$. However, the New Brunswick isolate proved to be different from the other 3 isolates (Fig. 1b), with homology of the predicted amino acid sequence $(80.5 \%)$ being much less than that at the nucleotide level $(89 \%)$. In this reading frame, many of the nucleotide variants possessed by the New Brunswick sequence occurred in the first or second amino acid coding position resulting in many non-synonymous substitutions. Despite the discrepancy of the New
Brunswick nucleotide and protein sequences, the predicted amino acid sequence of the Norwegian and New Brunswick isolates were similar to the Norwegian (Glesvaer/90) (AJ012285) and 'North American' (Bliss Harbour) (AF095255) sequences in the database.

Translation of the other large ORF in our sequence was compared with the NS2 protein/ORF1 predicted by the Norwegian (Glesvaer/90) sequence in the database (AJ012285). In this reading frame, all 4 isolates (Norwegian, Scottish, Nova Scotia and New Brunswick) showed remarkably high homology (>98\%) (Fig. 1c). 


\section{(a)}

AJO02475
N
S
NS
NB

AJ002475
N
S
NS
NB

AJO02475

N

NS

NB

AJ002475

N

NS

AJ002475

AJ 002475
N
S
NS
NB

AJ002475

N

NS

NB

AJ002475

$\mathrm{N}$
$\mathrm{N}$
$\mathrm{NS}$

NS

AJ002475

$\mathrm{N}$

NS

NB

AJ0 02475

N

NB

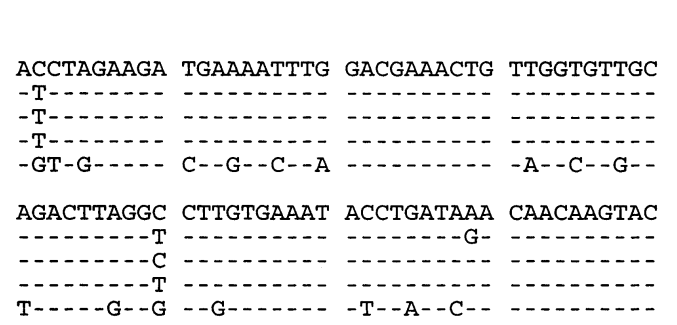

GATGAGgCAG AGAAAACTAG CTTAAGGAAG CCAATGGAAG

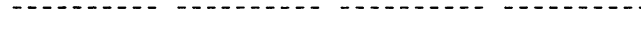

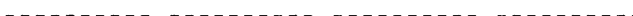

-

AAGCTTTCGA GAAGTCTATG AACGAAGAAT TTGTCGTACT

A

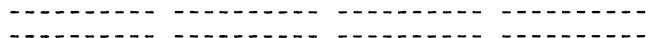

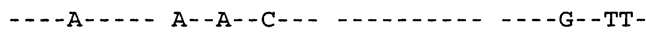

GAACAAAGGG AAATCAGCCA ATGACATTAT CTCCGACACA

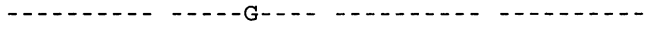

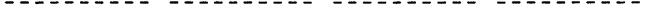

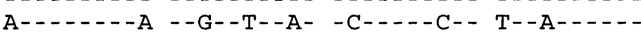

AACGCCGTGT GTAAATTCTG CGTTAAAAAC TGGATAGTAG

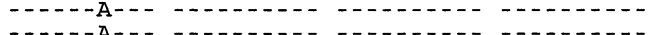

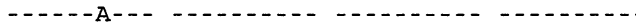

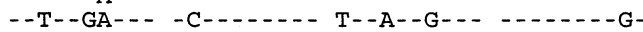

CAACAGGTTT CAGAGGAAGA ACCATGTCAg ACCTGATTGA

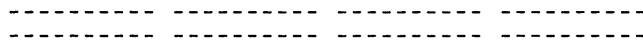

-

-

ACACCATTTC AGGTGTATGC AGgGGAAACA AGAAGTGAAA

-

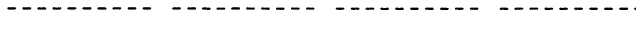

-

GGATACATAT GGAAACATAA ATACAACGAG AGACTTAAGA

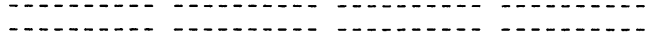

- - -

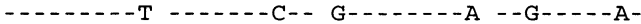

AJ002475
N
S
NS
NB
AJ002475
N
S
NS
NB
AJ002475
N
S
NS
NB
AJ002475
N
S
NS
NB

(b)
AJO02475
N
S
NS
NB

AJ 002475

$\mathrm{N}$

NS

AJ002475

N

NS

AJ 002475

$\mathrm{N}$

NS

NB

AJ002475
N
S
NS
NB

GAAAACAACT AAGCAAAGAA GAAGTTAAGT TCGACAGAGA

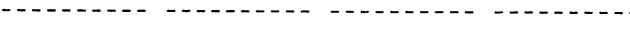

-

-

C.- G- - - -

GGAATACACC TCGAGAAGCT TCAGACTACT TTCATTCCTG

A--

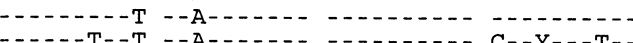

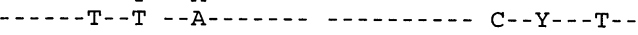

AAAAACAGCG AAAGAACTAA GCTGGAGCCG AGAGCAGTGT

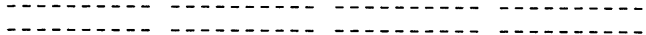
-

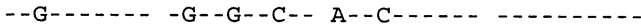

TCACAGCTGG AGTACCTTGG AGGGCTTTCA TCTTCGTTCT

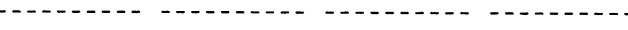
-

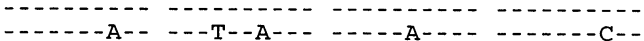

LEDENLDETV GVADLGLVKY LINNKYDEAE KTSLRKPMEE - - - -

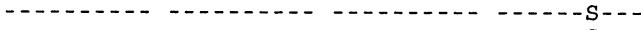

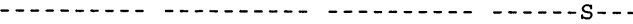

AFEKSMNEEF VVLNKGKSAN DIISDTNAVC KFCVKNWIVA

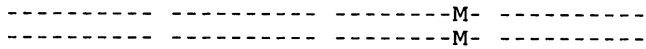

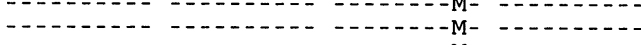
-

TGFRGRTMSD LIEHHFRCMQ GKQEVKGYIW KHKNERLKRK -.0.-. -

QLSKEEVKFD REEYTSRSFR LLSFLKNSET KLEPRAVFTA -

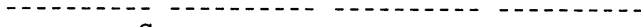

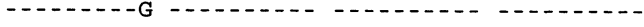
-

GVPWRAFIFV

(-10-

$(-1+2-1-2$

-

Fig. 2. Sequence comparison of ISAV in the region flanked by primers 245V/791L. (a) Nucleotide sequence; (b) predicted protein sequence. AJ002475: database sequence of ISAV from Norway; N: Norway; S: Scotland; NS: Nova Scotia; NB: New Brunswick

Thus, even though the New Brunswick isolate shared just $89 \%$ homology with the other 3 isolates at the nucleotide level, the nucleotide variants generally occurred in the 3rd amino acid coding position and resulted in synonymous, or silent, amino acid substitutions in the New Brunswick sequence.

RT-PCR across a 5' region of the putative polymerase gene on segment 2 using primers 245V/791L amplified a fragment of the expected size from segment 2 in all samples tested. Sequence analysis of the 245V/791L RT-PCR products showed a similar pattern of homologies seen with the segment 8 sequences. Again, the Nova Scotia samples shared a high degree of similarity $(>98 \%$ ) with the Norwegian and Scottish samples (Fig. 2a), while showing lower homology with the samples from New Brunswick.

RT-PCR across a more downstream region of the putative polymerase gene on segment 2 using primers
991V/1605L gave a product of the expected size in the Norwegian, Scottish and Nova Scotia samples; however, no amplification occurred in the 2 New Brunswick isolates. Sequencing of the amplified products revealed a homology of $>98 \%$ at the nucleotide level between the Nova Scotia samples and those from Norway and Scotland (Fig. 3a).

The 2 sequence segments from segment 2 were translated and compared at the protein level. There was high homology (>99\%) between the predicted protein sequence of the Nova Scotia, Scottish and Norwegian sequence across both regions of segment 2 studied (Figs. 2b \& 3b). For all strains the nucleotide substitutions generally occurred in the 3rd amino acid coding region, resulting in synonymous substitutions. Thus, even the predicted amino acid sequence of the New Brunswick sample shared high homology with the other isolates at the protein level. 
(a)

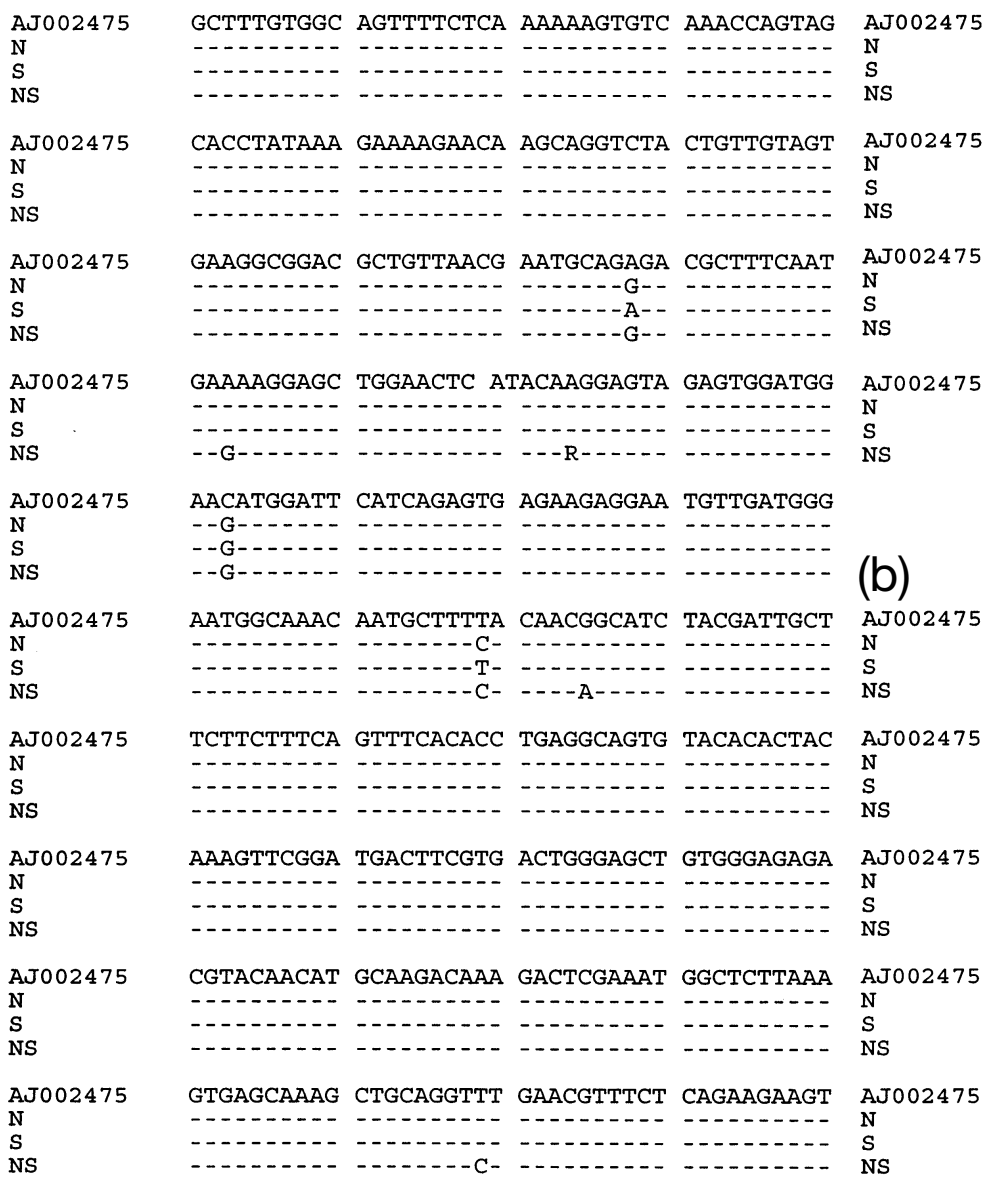

СTTTCTATGT GGAGGGGACG ACCTTCGAGT TCAACTCTAT -
GTTCGTAAGA GACGGGAAAG TCATGGCAAA TGGGGGCAAC

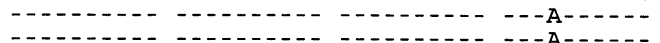
TTTGAAAACA TAACAGTTCC AGGTGGACTT GGGCCCTCAA

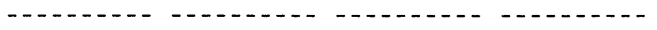
(1) CAGATCTATT TGTTGTTGGG AAACAGGCAA GAAACTCCAT

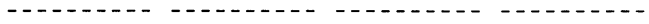

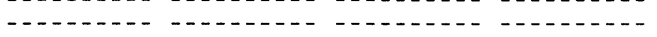

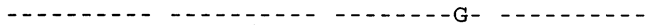

ALWQFSQKSV KPVAPIKKRTS RSTVVVKADA VNECRDAFNE

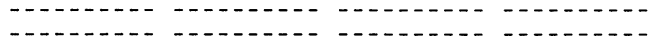

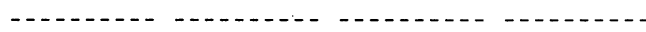

KELELIQGVE WMEHGFIRVRR GMLMGMANNA FTTASTIASS - - - - - - - D- - - - -

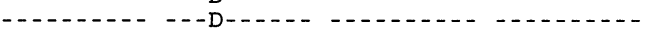
FSFTPEAVYT LQSSDDFVTGS CGRDVQHARQ RLEMALKVSK

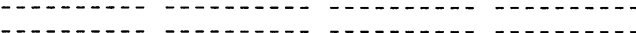

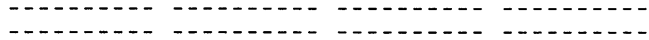

AAGLNVSQKK SFYVEGTTFEF NSMFVRDGKV MANGGNFENI

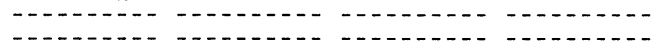

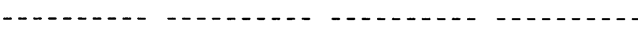

TVPGGLGPST DLFVVGKQAR N TVPG -

Fig. 3. Sequence comparison of ISAV in the region flanked by primers 991V/1605L. (a) Nucleotide sequence; (b) predicted protein sequence. AJ002475: database sequence of ISAV from Norway; N: Norway; S: Scotland; NS: Nova Scotia; NB: New Brunswick

\section{DISCUSSION}

In the present study we describe the identification of ISAV in Atlantic salmon from Nova Scotia under circumstances that are unusual for 2 reasons. The first is that, although the fish were positively identified as being infected with the virus, no ISAV-related pathology was seen. Although both rainbow trout and brown trout have been found to be carriers of ISAV with no clinical effects (Nylund et al. 1995a, Nylund \& Jakobsen 1995, Nylund et al. 1997), this is the first report of this phenomenon in (farmed) Atlantic salmon. Our findings may indicate that a carrier population of fish exists in which the reservoir of pathogen is too low to overwhelm the fish to the point of clinical infection. Indeed, the lack of any obvious cytopathic effect on the SHK cell line suggests a low viral titre since a threshold titre of virus is required before viral multiplication is made obvious by the destruction of host cells (Falk \& Dannevig 1995). Because of the prevailing low titre, a cytopathic effect is not possible even after repeated sub-passaging (authors' unpubl. data). Alternatively the Nova Scotia ISAV may be associated with the first functional difference seen among different ISAV samples, with this strain possessing lower infectivity, perhaps because of poor host cell adhesion or poor receptor-mediated endocytosis, for example. It is interesting to note that Kibenge et al. (2000) identified an isolate (HKS 36) that was found to be non-cytopathic but was positive for ISAV by RT-PCR. Although no further details of this strain were reported it is quite possible that this isolate is similar to that of the Nova Scotia ISAV described here.

Another unusual aspect of the current identification is that despite the existence of ISAV in neighbouring New Brunswick, the Nova Scotia strain has closer sequence homology to the Norwegian (and Scottish) strains. It has been suggested (Cunningham \& Snow 2000, Kibenge et al. 2000) that the sequence similarity between Scottish and Norwegian strains, and the dissimilarity with the New Brunswick strain result from geographic proximity. However, geographic proximity has clearly not resulted in similarity between the Canadian strains. One explanation for this may be that 
the Nova Scotia strain was unknowingly introduced to Nova Scotia through the transfer of aquaculturerelated material from the North Atlantic regions. Various hypotheses can be considered for this including intercontinental transport of salmonids, such as the various species of trout that are known to carry the virus but remain asymptomatic (Nylund \& Jakobsen 1995, Nylund et al. 1995a, 1997). Co-mingling migratory wild stocks in the North Atlantic could also accommodate a virus transfer. Alternatively, the Fundy (New Brunswick) strain may have experienced genetic drift from a strain that is more characteristic of the Atlantic Ocean as a whole (the identification described here was made in Cape Breton - the other side of Nova Scotia from the Bay of Fundy). Based on the mutation rate of the influenzae NS gene $\left(1.9 \times 10^{-3}\right.$ substitutions site $^{-1} \mathrm{yr}^{-1}$ ) (Fields 1996), the divergence of the New Brunswick strain would have occurred approximately 70 yr ago. Finally, while the Nova Scotia ISAV shows homology with the Norwegian and Scottish ISAV, the Nova Scotia isolate may actually be a distinct strain because it appears to be functionally different from both the Norwegian and Scottish strains in that it is unable to cause typical ISAV pathology. While no significant nucleotide differences were seen between these isolates in the segments studied here, these segments are not thought to be hypervariable and thus may not contain nucleotide, and thus amino acid, variants that would mark the Nova Scotia isolate as different from the Norwegian and Scottish isolates. It will be interesting to compare the sequences of other ISAV segments, particularly those encoding capsid proteins, to see whether there is a difference among the Nova Scotia, Norwegian and Scottish isolates.

While the issue of strain variation may be incompletely addressed by nucleotide homology, analysis of even a few genomic regions is useful for ensuring effective surveillance assays (by ensuring robust RTPCR assays) and aiding the characterisation of the ISAV genome. Fortuitously, primers FA3/RA3 on segment 8, which are used for routine RT-PCR, work for all isolates identified to date, but primers 991V/1605L on segment 2 do not work on the New Brunswick isolate and would give a 'false negative' result on these samples if used for routine RT-PCR. In addition, by comparing sequences from different isolates it is possible to ensure that what appear to be the coding ORFs for proteins actually exist in different strains. This is especially important in new virudae like ISAV. This is highlighted in our analysis of sequence variation in segment 8 between ISAV from New Brunswick and other geographic regions discussed below.

On the basis of information from other orthomyxovirudae, segment 8 is believed to encode 2 nonstructural proteins (NS1 and NS2). Sequencing across this region in all strains reveals the presence of several small ORFs, which were duly termed NS1 and NS2. However, when comparing the amino acid translation of the NS1 gene (ORF3 of Accession No. AJ012285) it was found that, unlike the other amino acid sequences of NS2 and RNAPB (Polymerase B) studied here, the New Brunswick strain shares just $80 \%$ homology with the Norwegian, Scottish and Nova Scotia strains. Closer examination revealed that in the NS1 reading frame, the majority of the nucleotide variants in the New Brunswick sequence occurred in the first or second amino acid coding position, resulting in many non-synonymous substitutions. The high degree of variation in this gene seems to be out of keeping with the other genes studied here, especially as segment 8 is thought to be hypovariable compared with segments encoding the haemagglutinin or neuraminidase proteins (Cunningham \& Snow 2000). Although it is possible that this much variation is tolerated in the NS1 gene, because it is believed to be an internal, structural gene, it is also possible that the predicted amino acid sequence for the NS1 gene in the database is incorrect and that NS1 is encoded by the reading frame that also encodes NS2.

Until now, ISAV researchers have assumed that each of the large ORFs in segment 8 encodes a single NS gene. However, this is not true of other orthomyxovirudae such as the influenzae virus. Generally, NS1 is considered to be the larger of the 2 genes, and is colinear with genomic RNA (Fields et al. 1996). In contrast, the smaller NS2 gene is believed to arise from a spliced, and partially overlapping, mRNA in the same reading frame as NS1. Because ISAV is an orthomyxolike virus, it is possible that both the NS1 and NS2 genes are translated in the same reading frame, with one of the products resulting from an internal splicing event. Thus, the predicted amino acid sequence of the NS1 gene might be coded for within the same reading frame as NS2. If this is the case, nucleotide substitutions identified in the New Brunswick isolate would generally affect the third amino acid coding resulting in synonymous or silent mutations. This would be more in accordance with the similarity in amino acid sequence seen among the 4 isolates considered in the present study. Thus, while analysis of strain variation by nucleotide variation may be limited by the 2 ISAV segments characterised to date, it may provide a useful means by which to double check the ongoing genomic characterisation of this virus.

Analysis of the Nova Scotia ISAV described here highlights the need for a concerted approach to strain variation studies and genome characterisation. Although no salmon mortalities have yet affected the Nova Scotia industry it is hoped that the availability of sensitive and robust diagnostic techniques that take into account strain variation may provide a pre-emptive ap- 
proach for effective monitoring and preventative practices. It is hoped that by rigorous and judicious use of a monitoring program, a tragedy similar to the one experienced in New Brunswick can be avoided.

Acknowledgements. The authors would like to thank A. M. McKinnon for providing culture results associated with wild salmon. This work was supported by the Nova Scotia Department of Fisheries and Aquaculture and the New Brunswick Department of Fisheries and Aquaculture.

\section{LITERATURE CITED}

Blake S, Bouchard D, Keleher W, Opitz HM, Nicholson BL (1999) Genomic relationships of the North American isolate of infectious salmon anemia virus (ISAV) to the Norwegian strain of ISAV. Dis Aquat Org 35:139-144

Bouchard D, Keleher W, Opitz HM, Blake S, Edwards KC, Nicholson BL (1999) Isolation of infectious salmon anemia virus (ISAV) from Atlantic salmon in New Brunswick, Canada. Dis Aquat Org 35:131-137

Cunninghom CO, Snow M (2000) Genetic analysis of infectious salmon anaemia virus (ISAV) from Scotland. Dis Aquat Org 41:1-8

Dannevig BH, Falk K, Namork E (1995) Isolation of the causal virus of infectious salmon anaemia (ISA) in a long-term cell line from Atlantic salmon head kidney. J Gen Virol 76: 1353-1359

Evensen Ø, Thorud KE, Olsen YA (1991) A morphological study of the gross and light microscopic lesions of infectious anaemia in Altantic salmon (Salmo salar). Res Vet Sci 51:215-222

Falk K, Dannevig BH (1995) Demonstration of infectious salmon anaemia (ISA) viral antigens in cell cultures and tissue sections. Vet Res 26:499-504

Falk K, Namork E, Rimstad E, Mjaaland S, Dannevig BH (1997) Characterization of infectious salmon anemia virus, an orthomyxo-like virus isolated from Atlantic salmon (Salmo salar L.). J Virol 71:9016-9023

Fields BN, Knipe DM, Howley PM (1996) Fundamental virology, 3rd edn. Lippincott-Raven Press, Philadelphia, p 605-647

Kibenge FS, Lyaku JR, Rainnie D, Hammell KL (2000) Growth of infectious salmon anaemia virus in CHSE-214 cells and

Editorial responsibility: Jo-Ann Leong,

Corvalis, Oregon, USA evidence for phenotypic differences between virus strains. J Gen Virol 1:143-150

Krossøy B, Hordvik I, Nilsen F, Nylund A, Endresen C (1999) The putative polymerase sequence of infectious salmon anemia virus suggests a new genus within the Orthomyxoviridae. J Virol 73:2136-2142

Lovely JE, Dannevig BH, Falk K, Hutchin L, MacKinnon AM, Melville KJ, Rimstad E, Griffiths SG (1999) First identification of infectious salmon anaemia virus in North America with haemorrhagic kidney syndrome. Dis Aquat Org 35: 145-148

Melville KJ, Griffiths SG (1999) Absence of vertical transmission of infectious salmon anemia virus (ISAV) from individually infected Atlantic salmon Salmo salar. Dis Aquat Org 38:231-234

Mjaaland S, Rimstad E, Falk K, Dannevig BH (1997) Genomic characterization of the virus causing infectious salmon anemia in Atlantic salmon (Salmo salar L.): an orthomyxolike virus in a teleost. J Virol 71:7681-7686

Mullins JE, Groman D, Wadowska D (1998) Infectious salmon anaemia in salt water Atlantic Salmon (Salmo salar L.) in New Brunswick, Canada. Bull Eur Assoc Fish Pathol 18: 110-114

Nylund A, Jakobsen (1995) Sea trout as a carrier of infectious salmon anaemia virus. J Fish Biol 47:174-176

Nylund A, Alexandersen S, Rolland JB (1995a) Infectious salmon anemia virus (ISAV) in brown trout. J Aquat Anim Health 7:236-240

Nylund A, Hovland T, Watanabe K, Endressen C (1995b) Presence of infectious salmon anaemia virus (ISAV) in tissues of Atlantic salmon, Salmo salar L. collected during three separate outbreaks of the disease. J Fish Dis 18: $135-145$

Nylund A, Kvenseth AM, Krossøy B, Hodneland K (1997) Replication of the infectious salmon anaemia virus (ISAV) in rainbow trout, Oncorhynchys mykiss (Walbaum). J Fish Dis 20:275-279

Rodger HD, Turnbull T, Muir F, Millar S, Richards RH (1998) Infectious salmon anaemia (ISA) in the United Kingdom. Bull Eur Assoc Fish Pathol 18:115-116

Rowley HM, Campbell SJ, Curran WL, Turnbull T, Bryson DG (1999) Isolation of infectious salmon anaimia virus (ISAV) from Scottish farmed Atlantic salmon (Salmo salar L.). J Fish Dis 22:483-487

Thorud K, Djupvik HO (1988) Infectious salmon anaemia in Atlantic salmon (Salmo salar L.). Bull Eur Assoc Fish Pathol 8:109-100

Submitted: March 21, 2000; Accepted: May 15, 2000

Proofs received from author(s): March 19, 2001 